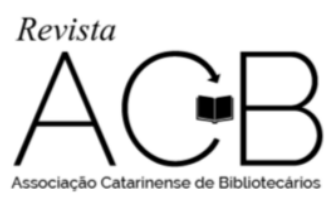

\title{
AS CONTRIBUIÇÕES DA DOCUMENTAÇÃO NO DESENVOLVIMENTO DAS PRÁTICAS BIBLIOTECÁRIAS EM BIBLIOTECA UNIVERSITÁRIA: DIÁLOGOS COM PAUL OTLET
}

\author{
Jorge Santa Anna ${ }^{1}$ \\ jorjao20@yahoo.com.br \\ Élida Mara Mascarenhas Pieri² \\ elidapieri@gmail.com
}

Resumo: Este estudo versa acerca das práticas documentárias propostas pela Documentação e refletidas por Otlet e a adesão dessas práticas pelas bibliotecas universitárias da contemporaneidade. Objetiva analisar essas práticas no âmbito de uma biblioteca universitária, destacando os produtos e serviços oferecidos pela referida unidade de informação. Para tanto, apresenta referencial teórico breve sobre os princípios da Documentação com base nas teorias de Otlet e realiza pesquisa documental e observação em um contexto real, haja vista perceber/identificar, no referido contexto, as práticas documentárias elucidadas pela literatura. Em linhas gerais, constataram-se inúmeras práticas documentárias realizadas no ambiente in loco, confirmando que a maioria desses fazeres é realizado no setor de processamento técnico, por meio da elaboração de registros catalográficos, resumos e resenhas, como também a confecção de outros documentos, como manuais de serviço, boletins bibliográficos e livro de Normalização. Além disso, a unidade utiliza de recursos informatizados no intuito de permitir uma maior aproximação entre os usuários, tais como catálogos e bases de dados eletrônicos, assim como o uso das redes sociais, de modo que, por meio do compartilhamento, amplia-se o acesso à informação, por conseguinte, a geração de novos conhecimentos e documentos, tendência essa que confirma a concretização dos ideais de universalização propostos por Otlet.

Palavras-chave: Biblioteconomia. Bibliotecas universitárias. Documentação. Práticas documentárias. Universalização do conhecimento.

\section{INTRODUÇÃO}

A biblioteca universitária constitui uma das principais unidades e serviços de informação, a qual se configura como um importante elemento que participa do processo de democratização da informação e desenvolvimento do conhecimento na sociedade pós-moderna.

O crescimento dessa unidade e sua valorização como partícipe do processo de desenvolvimento institucional e social deve-se, em grade parte, à contribuição oriunda das novas tecnologias, como também deve-se à adoção de práticas e serviços inovadores, os quais são sustentados por meio do desenvolvimento

\footnotetext{
1 Possui graduação em Biblioteconomia pela Universidade Federal do Espírito Santo (UFES, 2012). Atualmente, é instrutor de cursos sobre Normalização e Editor de Textos para Trabalhos Acadêmicos e Redação Oficial no Departamento de Pessoas da UFES; mestrando do Programa de Pós-Graduação em Gestão e Organização do Conhecimento da Universidade Federal de Minas Gerais (UFMG); bolsista do projeto elaboração e implantação de uma política de periódicos e construção do portal de periódicos de Minas Gerais, financiado pela Fundação de Amparo à Pesquisa de Minas Gerais (FAPEMIG); membro do grupo de pesquisa Informação e sistemas de informação: Estudos de usuários e usos, financiado pelo CNPQ; atua no ramo da consultoria informacional, com foco em normalização, estruturação e revisão de projetos e pesquisas acadêmico-científicas; ministra aulas, cursos e treinamentos sobre metodologia científica e leciona nos cursos de Biblioteconomia e Administração; e é revisor e assessor do periódico Pró-Discente do Programa de Pós-Graduação em Educação da UFES.

2 Mestranda no Programa de Pós-Graduação em Gestão e Organização do Conhecimento da Escola de Ciência da Informação da UFMG. Especialista em Gestão de Instituições Federais de Educação Superior (GIFES) pela Faculdade de Educação (FAE) da UFMG. Bacharel em Comunicação Social, com ênfase em Publicidade e Propaganda pelo Centro Universitário Newton Paiva. Servidora Técnico-Adminstrativa em Educação da UFMG.
} 
científico proporcionado por inúmeras áreas do conhecimento.

Como bem apontou Araújo (2014), na sociedade contemporânea, as diversas instituições que se colocam a serviço da informação e da cultura, tais como arquivos, museus e bibliotecas (essas últimas incluem-se as diversas modalidades existentes, tais como bibliotecas especializadas, universitárias, escolares etc.), apropriam-se dos paradigmas e concepções fornecidos a partir da consolidação de áreas científicas, como a Arquivologia, Biblioteconomia, Ciência da Informação e Museologia e as diversas disciplinas atreladas a essas áreas.

Inúmeros estudos relatam acerca das rápidas mudanças que ocorrem no âmbito das bibliotecas universitárias, em que produtos e serviços biblioteconômicos são redefinidos, considerando novas necessidades demandadas, como também novas possibilidades a serem acrescentadas a tais práticas, conforme relatado nas pesquisas de Aguiar e Silva (2013), Carvalho (2004), Leitão (2005), Santa Anna (2015), dentre outros estudos.

Em linhas gerais, esses estudos abordam aspectos relacionados às transformações sociais, tais como o trabalho colaborativo que viabiliza a socialização do conhecimento (CARVALHO, 2004); a reconfiguração dos serviços e produtos com base na percepção dos usuários (LEITÃO, 2005); o uso das novas tecnologias, como forma de aproximação com as demandas informacionais (AGUIAR; SILVA, 2013) e a oferta diversificada de produtos e serviços à luz de diferentes paradigmas (SANTA ANNA, 2015).

Esse último estudo afirma que a biblioteca universitária precisa de se reinventar, haja vista, inserir-se em um contexto híbrido e multifacetado, tornando-se um organismo dinâmico, em crescimento, mas, conforme apontou Carvalho (2004), sem perder a sua essência como disseminadora do conhecimento, através de práticas documentárias realizadas com o uso de diferentes tecnologias.

Ao falar das práticas documentárias, vêm à tona, as contribuições determinadas a partir do desenvolvimento da Documentação, no século XVI, viabilizado com o aumento da produção bibliográfica, a qual gerou a necessidade de novas ferramentas de organização e recuperação das coleções (SIQUEIRA, 2010).

Assim, confirma-se que inúmeras práticas realizadas nas bibliotecas universitárias atem-se aos métodos de descrição e representação da informação realizados no âmbito da organização da informação bibliográfica. No entanto, é errôneo considerar que as práticas documentárias estejam presentes, tão somente, nesses fazeres.

A pesquisa de Segundo (2011), por exemplo, garante que as práticas documentárias idealizadas e visionalizadas por Paul Otlet, no século XIX, estendem-se até os dias de hoje, tendo como máxima o uso das tecnologias da informação e comunicação, as quais sustentam uma dinâmica colaborativa em níveis globais (o autor cita como principal exemplo, o uso do facebook), assim como presumia a ideia do livro universal proposta pelo pai da documentação.

No âmbito da Documentação, Otlet representou um ícone na organização e disseminação do conhecimento universal, como também representou um verdadeiro agente de transformação para as unidades de informação que se colocam a serviço da organização documental, atividades cabíveis às bibliotecas, arquivos e museus.

Sendo assim, este estudo versa acerca das práticas documentárias propostas pela Documentação e refletidas por Otlet e a adesão dessas práticas pelas bibliotecas universitárias da contemporaneidade. Objetiva analisar essas práticas no âmbito de uma biblioteca universitária, destacando os produtos e serviços oferecidos pela referida unidade de informação.

Para tanto, apresenta referencial teórico breve sobre os princípios da Documentação com base nas teorias de Otlet e realiza pesquisa documental e observação em um contexto real, haja vista perceber/identificar, no referido contexto, as práticas documentárias elucidadas pela literatura.

\section{REVISÃO DE LITERATURA}

As bibliotecas universitárias estão em constante desenvolvimento ao considerarem as expectativas, desejos e necessidades informacionais de seus principais usuários, os quais são, primordialmente, todos os 
atores pertencentes à universidade - considerando-se discentes, docentes e colaboradores - haja vista alimentar as atividades de pesquisa, de ensino e de extensão (CHAGAS; SOUZA, 2002).

Os serviços e produtos oferecidos nessas unidades são dos mais variados, contemplando desde atividades meramente informacionais como também atividades de cunho cultural e recreativo (SANTA ANNA, 20015). Todavia, as atividades em prol da formação e desenvolvimento das coleções constituem o cerne das atividades bibliotecárias desenvolvidas nesses espaços (MACIEL; MENDONÇA, 2006).

As atividades realizadas no âmago da organização da informação, qual sejam, as práticas de catalogação, classificação e indexação, incluindo-se tratamento informacional a diferentes itens, constituem fazeres tradicionais dessas unidades, mas que vêm se evoluindo ao longo dos tempos, através de processos de colaboração, viabilizados com o uso de novas tecnologias, o que desperta um intenso trabalho de socialização entre diferentes unidades (CARVALHO, 2004).

$\mathrm{Na}$ atualidade, a biblioteca universitária situa-se em momento de encruzilhada (CUNHA, 2011), deixando-se de ser um ambiente fechado e isolado para inserir-se a um ambiente diversificado/misto, em que operem diferentes processos de trabalho e diferentes tecnologias para facilitar o processo de tratamento documentário quanto o acesso a esses documentos por meio de diferentes recursos da realidade virtual (SANTA ANNA, 2015).

Mesmo sendo uma instituição que oferece produtos e serviços diversificados, sejam quanto ao uso de tecnologias variadas, seja no tipo de serviço ou função prestado a sua clientela, uma das práticas tradicionais fortemente instituídas no bojo dessas unidades, diz respeito ao tratamento documentário ou informacional realizado. De qualquer forma, tudo que a biblioteca se propõe a oferecer deve considerar as necessidades de seus usuários e adentrar-se a padrões de qualidade (RAMOS, 2000).

Assim, a elaboração de produtos capazes de viabilizar a consulta e localização aos itens armazenados em uma coleção constitui o alicerce que despertou o desenvolvimento da Documentação. Para Ortega (2004), a Documentação é uma disciplina preocupada com a elaboração de registros do conhecimento dos mais variados, registros esses que representam detalhes do item informacional, sejam esses intrínsecos quanto extrínsecos, mas que, quando sistematizados em um sistema de recuperação proporcionarão a localização do item, assim como provocarão aos usuários conhecimento prévio sobre determinadas características do item.

Segundo a autora supracitada, é através da explosão bibliográfica que se sentiu a necessidade de elaboração de registros mais detalhados e diversificados, representando verdadeiros subprodutos do item informacional. Portanto, a Documentação representou uma evolução dos métodos tradicionais de representação até então viabilizados pela Bibliografia. É através de novos métodos e técnicas para representar o documento em um conjunto maior que a prática de resumos, elaboração de fichas catalográficas, extração de palavras-chaves, dentre outras atividades ganharam força no contexto de bibliotecas quanto de arquivos.

As práticas propostas pela Documentação estão, em um primeiro momento, diluídas às atividades que sustentam o processo de organização de documentos, tendo em vista a formação de coleções, as quais constituirão os acervos de diferentes unidades de informação. Com efeito, o ato de indexar, classificar e catalogar os itens permite maior facilidade de localização do item e do uso da informação, como também gera novos registros de representação (ORTEGA, 2004).

A respeito do processo de representação viabilizado pela Documentação, Novelinho (1996) ensina que esse trabalho desenvolvido junto a materiais dos mais diferentes gêneros e formatos, trata da construção de abreviaturas dos materiais, sendo que nesses registros existem mensagens que são transmitidas do item a seus usuários, o que afere uma maior aproximação entre a informação e seu receptor, por conseguinte, consolida-se, nesse âmbito, o processo comunicativo.

Em linhas gerais, as práticas de construção dos registros do conhecimento, normalmente, nos dias atuais, são realizadas nas bibliotecas em espaços específicos, denominados de processamento técnico, em que os materiais adquiridos são catalogados, indexados e classificados, conforme regras de representação existente na biblioteca (SANTA ANNA, 2016).

No entanto, não se pode limitar as práticas documentárias, tão somente, nesses espaços, pois as formas 
de representação também podem ser realizadas em outros contextos e unidades de informação, tais como em arquivos, museus, centros de informação e cultura, como também em editoras, em que, comumente, é realizada a elaboração de resumos, resenhas e demais mecanismos de representação durante o processo de editoração. Também é importante mencionar o trabalho de representação dos documentos realizado em ambientes e plataformas digitais, através da construção de metadados e ontologias, considerando os relacionamentos estabelecidos pelas linguagens documentárias disponibilizadas nos ambientes informatizados (ARAÚJO, 2014).

Para Araújo (2010), não resta dúvida de que a tentativa de se organizar a produção de conhecimento, como a publicação de artigos em periódicos científicos, no século XIX, provavelmente, constituiu os grandes fatores de ampliação das práticas documentárias, como despertou a valorização, crescimento e reconhecimento da Documentação mundo afora.

Para o referido autor, a Documentação é uma disciplina que sustenta inúmeras áreas do conhecimento, principalmente as áreas que tem a informação como seu objeto de estudo, como acontece com a Arquivologia, Biblioteconomia, Ciência da Informação e a Museologia. A documentação, segundo Araújo (2010), insere-se em um paradigma patrimonialista, ou seja, a preocupação é sistematizar a produção documental que resguarde a história e cultura de uma dada sociedade.

Importante mencionar, nesse enfoque, que, essas áreas, de um modo geral, ao adotarem as concepções oriundas da Documentação, criam um vínculo de aproximação, em que comungam de ideais similares, por meio de técnicas que conservam, preservam, coligem, ordenam, classificam e difundem documentação produzida em um contexto social (ARAÚJO, 2010).

Para Oliveira (2004), o desenvolvimento da Documentação, juntamente com a Recuperação da Informação e os discursos sobre interdisciplinaridade são as bases sustentadoras da Ciência da Informação, área mais recente, desenvolvida a partir da década de 1960. A Documentação surge à medida em que o conceito de documento é revisto, deixando seu caráter meramente físico para adentrar-se a questões de conteúdo documentário, o que desperta uma nova preocupação, focada não no documento, mas sim, na informação que está materializada no suporte documental.

De qualquer forma, essa disciplina, embora tenha suas raízes às primeiras técnicas de representação ocorridas em bibliotecas da Antiguidade, fato esse que a aproxima da Biblioteconomia, é somente com Otlet que ela se consolida a partir de novas proposições paradigmáticas. Assim, é importante considerar que:

[...] A principal preocupação da Documentação estava no acesso à informação, nos mais diversos suportes documentais e em diferentes centros de informação (biblioteca, arquivo, museu), enquanto a Biblioteconomia estava desenvolvendo sua habilidade, em nível restrito, para proceder com a utilidade do livro e, em nível mais amplo, para indicar a atividade de gestão e organização de acervos de bibliotecas (SILVA; FREIRE, 2012, p. 9).

Na visão de Ortega (2004), Otlet condenou a forma de organização e desenvolvimento de livros nas tradicionais bibliotecas anteriores a seu tempo. Ou seja, considera o pai da Documentação que os métodos custodiais de guarda e conservação de documentos, assim como a simplicidade na elaboração das listas bibliográficas representavam um atraso para a produção de conhecimento.

Nesse enfoque, era preciso romper com práticas tecnicistas de conservação e localização, para adentrar-se a um fazer mais abrangente, permitindo que a informação contida no documento entrasse em um processo de circulação, através de redes de relacionamento, o que condicionaria a ampliação do acesso e do uso da informação (SIQUEIRA, 2010).

No entendimento de Silva e Freire (2012), Otlet, através de sua obra "Tratado de Documentação", estabeleceram-se alguns princípios para a Documentação, consistindo em poder oferecer informação sobre todo tipo de fato e de conhecimento, a partir de quatro fundamentos, a saber:

1 - o registro do pensamento humano e da realidade exterior em elementos de natureza material, ou seja, documentos; 
2 - a conservação, circulação, atualização, catalografia, descrição e análise desses documentos;

3 - a elaboração, com a ajuda de documentos simples, dos documentos mais complexos, e com a ajuda dos documentos particulares, o conjunto desses documentos;

4 - em último grau, o registro dos dados cada vez mais completo, exato, preciso, simples, direto, rápido, sinótico, de forma simultaneamente analítica e sintética; seguindo um plano cada vez mais integral, enciclopédico, universal e mundial.

Ainda em Silva e Freire (2012), reflete-se acerca das repercussões que as ideias otletianas tiveram no desenvolvimento dos atuais sistemas de recuperação da informação e a inserção desses instrumentos no contexto da web, o que para Segundo (2011), não há possibilidade de distanciar a visão de Otlet com a sociedade colaborativa em que as unidades de informação estão inseridas.

Nas palavras de Silva e Freire (2012, p. 10) reflete-se que:

[...] Otlet procurou incessantemente sintetizar a informação, visando tornar o acesso mais facilitado e rápido, assim como tornando a informação mais confiável; [tendo em vista viabilizar] condições para que as informações pudessem ser extraídas do documento, transcritas em fichas e correlacionadas com assuntos semelhantes, com vistas a formar uma rede conceitual (rede de informações) dinâmica, de acordo com a necessidade dos usuários.

Considera-se que a escassez de recursos tecnológicos presentes na época de Otlet desencadeou inúmeras dificuldades para que seu projeto fosse concretizado. Assim, para Segundo (2011), é apenas com o desenvolvimento tecnológico que se sucedeu nas últimas décadas do século XX e com as transfigurações de novos canais de comunicação e o uso acentuado da internet que a intenção desse importante teórico é concretizada.

Assim, o uso das tecnologias de informação e comunicação no âmago das unidades de informação proporcionou novas formas de atuação e intervenção dessas unidades na sociedade atual. Esse uso facilita o trabalho profissional, assim como apontou Carvalho (2004), através do processo de colaboração interbibliotecária, como também facilita, segundo Santa Anna (2015), o acesso a diversas fontes de informação armazenadas nos acervos documentários.

Observa-se, nesse contexto, que as práticas de tratamento informacional oriundas com o desenvolvimento da Documentação são refletidas nas práticas bibliotecárias, como nos ensina Segundo (2011). O referido autor desmistifica o fato de que esses fazeres são restritos, tão somente, à elaboração de produtos de representação em suportes impressos. Ao contrário, com o uso das tecnologias de ponta, as práticas documentárias tornam-se cada dia mais ampliadas, tendo o usuário cada vez mais participação nesse processo.

Essa evolução de tais práticas demonstra que as ideias propostas por Otlet, no século XIX, não constituem mais um sonho ou ilusão, mas uma realidade. Ou seja, a tentativa de se organizar um "livro universal", em que a produção bibliográfica mundial pudesse ser tratada de forma colaborativa e acessada de diferentes formas e em variados contextos e locais, concretizou-se a partir do uso do surgimento dos canais eletrônicos, em que informação é compartilhada, sem considerar as limitações de tempo e de espaço (SEGUNDO, 2011).

Vê-se, portanto, a evolução da Documentação, em que novas práticas são realizadas que extravasam a elaboração de registros documentários materializados em um suporte, ideia defendia por muito tempo pela Biblioteconomia (SIQUEIRA, 2010). A Documentação, segundo Otlet (1997, p. 115), deve constituir-se como um conjunto de atividades que irão facilitar o acesso e uso dos documentos, através da elaboração de produtos de representação e recuperação. Assim, segundo esse teórico, as práticas documentárias devem "[...] acompanhar o documento desde o instante em que ele surgiu da pena do autor até o momento em que impressionava o cérebro do leitor" (OTLET, 1997, p. 115).

A tese de Otlet não pode ser vista como algo que permeava apenas as atividades desenvolvidas com tecnologias existentes no decorrer do século XIX, mas representou um despertar para o desenvolvimento de novas técnicas e métodos de representação e armazenamento de documentos em ambientes eletrônicos, 


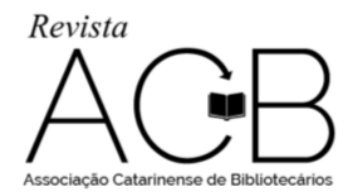

As contribuições da documentação no desenvolvimento das práticas bibliotecárias em biblioteca universitária: diálogos com Paul Otlet - Jorge Santa Anna e Élida Mara Mascarenhas Pieri

iniciado nas últimas décadas do século XX e vem se desenvolvendo de forma acelerada nos dias de hoje. Na visão de Siqueira (2010, p. 59),

Em um contexto de ciclos de progresso das civilizações mundiais, que para cada nova tecnologia abria-se espaço para novos conflitos internos e externos, a obra de Otlet se encaixava nesse viés, pois tinha como um de seus mais ambiciosos intentos o armazenamento das representações de todo o conhecimento humano em um único local, projeto que fomentaria a paz mundial. Além disso, [...] [a tese de Otlet] antecipou o surgimento de novas tecnologias, em especial os sistemas de hipertexto e hipermídia, frutos da revolução tecnológica desencadeada depois da II Guerra Mundial.

Corrobora esse pensamento, Segundo (2011), para quem Otlet é considerado como um precursor dos atuais sistemas de informação, defendendo a proposta de que as relações entre os elementos que compõe o mundo são essenciais para viabilizar o acesso universal a esses elementos, o que ocasionaria a paz mundial. É através das técnicas de relacionamento que foi possível desenvolver sistemas classificatórios - como o Sistema de Classificação Universal (CDU) - capazes de armazenar, de forma sistematizada e relacional, os itens de uma coleção, desencadeando facilidades na localização e acesso.

Além disso, importante destacar a capacidade visionária desse teórico, uma vez que no ano de 1895, ele anteviu o que iríamos ver acontecer na década de 1990: informações dispostas na forma de rede, sendo produzidas, gerenciadas e disseminadas por meio de ações colaborativas, tais como percebemos nos atuais sistemas de recuperação da informação informatizados, como no uso de ferramentas e instrumentos do ambiente digital, como por exemplo, as redes sociais e o hipertexto. Isso nos remete a afirmar a ampliação das práticas documentárias para além do ambiente físico da biblioteca, ou seja, a Documentação ampliou seu escopo de atuação com o desenvolvimento da internet, conforme apontado no estudo de Segundo (2011).

Portanto, na atualidade, as unidades de informação devem recorrer a todos esses princípios, teorias e paradigmas, de modo a refazerem seus processos de trabalho, por meio da oferta de produtos e serviços inovadores. Considerar os paradigmas das ciências no contexto pragmático, sustentando práticas profissionais, constitui uma necessidade a ser pensada em todos os segmentos sociais (VIEIRA; ARDIGO, 2015).

Pensar essas considerações e mudanças no bojo das unidades de informação faz-se necessário, haja vista adequar a unidade ao contexto competitivo, mutante e instável da atualidade (VIEIRA; ARDIGO, 2015). Além de redefinir produtos e serviços em informação, segundo esses autores, é preciso elaborar propostas mais audaciosas com base em planos de melhoria contínua, no intuito de medir/avaliar as decisões tomadas e os impactos provocados na promoção de mudanças (quebra de paradigmas).

\section{MATERIAIS E MÉTODOS}

O desenvolvimento deste trabalho apoiou-se na pesquisa do tipo bibliográfica, documental e estudo de caso. A primeira refere-se ao levantamento de trabalhos que versam sobre um determinado assunto contemplado em uma área específica de conhecimento. Normalmente, a pesquisa bibliográfica constitui o primeiro passo no desenvolvimento de qualquer pesquisa (VERGARA, 2007). A segunda modalidade de pesquisa relaciona-se à consulta de materiais não publicados, incluindo-se, documentos oriundos de atividades institucionais/organizacionais (GIL, 2008). Por fim, a terceira modalidade de pesquisa trata-se de uma intensa observação a uma prática, a um processo ou a um evento, considerando contexto específico em que esses se desenvolvem (LAKATOS; MARCONDES, 2003).

Para realização da pesquisa bibliográfica, recorreu-se a livros e artigos científicos que versam sobre Documentação e suas relações com as práticas bibliotecárias, considerando os trabalhos de Paul Otlet além de trabalhos que retratam as transformações nas bibliotecas universitárias. Dos autores investigados, destacam-se como principais: Araújo (2010, 2014), Carvalho (2004), Oliveira (2005), Ortega (2004), Santa Anna (2015, 2016), Segundo (2011), Silva e Freire (2012), Siqueira (2010), dentre outros.

No que se refere ao estudo de caso, realizou-se duas visitas a uma biblioteca universitária da esfera 
privada, sendo que os pesquisadores utilizaram da técnica de observação direta em todos os departamentos da unidade, considerando, de modo especial, os produtos e serviços bibliotecários realizados, assim como as práticas e processos de trabalhos desenvolvidos.

Quanto à pesquisa documental, realizou-se consulta ao manual de serviços da referida unidade de informação, assim como análise dos produtos e serviços bibliotecários disponibilizados no website da biblioteca universitária aqui investigada.

A biblioteca universitária aqui analisada está inserida em um campus universitário, o qual são ministrados dez cursos de Graduação e oito de Pós-graduação, sendo cinco de Especialização, dois Mestrados e um Doutorado. Nesse campus estão presentes cinco centros de ensino, tendo em cada centro, dois cursos e uma biblioteca setorial específica para atender os referidos cursos. Portanto, nessa universitária, há um sistema integrado de bibliotecas, composto por seis bibliotecas, quais sejam: uma central (sujeito desta pesquisa) e cinco setoriais.

As atividades de aquisição das obras para composição dos acervos de todas as bibliotecas são realizadas apenas pela biblioteca central, sendo que nas setoriais realizam-se apenas serviços de referências, empréstimo e devolução de materiais, consulta ao acervo e acertos de multa.

Com efeito, a biblioteca central está dividida em oito setores, sendo que em cada setor são realizadas atividades diferentes, considerando a formação de produtos e serviços bibliotecários dos mais diferenciados, logo, as práticas bibliotecárias também são das mais diversificadas. Após análise da realidade local, considerando a pesquisa documental e estudo de caso, os dados coletados foram agrupados em forma de quadro, demonstrando as atividades biblioteconômicas realizadas e a sua devida comparação com os princípios e práticas emanados da Documentação. Os resultados dessas análises estão descritos na seção seguinte.

\section{RESULTADOS E DISCUSSÃO}

Os processos de análise que permearam o estudo de caso e a pesquisa documental tiveram como fio condutor de investigação um roteiro contendo tópicos específicos, contemplando perguntas a serem respondidas com base na realidade e nos documentos analisados. Esse roteiro foi construído com base nos principais princípios e ideais da Documentação, conforme elucidado pela literatura consultada.

A formulação desses princípios sustentou-se nas propostas de Otlet e que foram demonstradas no estudo de Silva e Freire (2012), considerando-se os seguintes aspectos da Documentação: 1 - o registro do pensamento humano e da realidade exterior em elementos de natureza material, ou seja, documentos; 2 - a conservação, circulação, atualização, catalografia, descrição e análise desses documentos; 3 - a elaboração, com a ajuda de documentos simples, dos documentos mais complexos, e com a ajuda dos documentos particulares, o conjunto desses documentos; 4 - em último grau, o registro dos dados cada vez mais completo, exato, preciso, simples, direto, rápido, sinótico, de forma simultaneamente analítica e sintética, seguindo um plano cada vez mais integral, enciclopédico, universal e mundial. Além disso, considerou-se na formulação dos critérios a serem observados e identificados, os estudos de Araújo (2014), Segundo (2011) e Siqueira (2010), no que se refere às práticas e ideais inovadores da Documentação a partir do uso dos recursos informatizados.

Portanto, tendo como norte os princípios descritos por Otlet citado por Silva e Freire (2012), foi possível identificar algumas práticas documentárias realizadas em setores específicos da biblioteca. Os resultados dessa observação estão mencionados no quadro 1. 
Quadro 1 - Identificação dos princípios de documentação propostos por Otlet nas práticas bibliotecárias realizadas na biblioteca universitária

\begin{tabular}{|c|c|c|}
\hline Princípios segundo Otlet & $\begin{array}{l}\text { Práticas documentárias } \\
\text { identificadas }\end{array}$ & $\begin{array}{c}\text { Setor que } \\
\text { realiza }\end{array}$ \\
\hline $\begin{array}{l}1 \text { - o registro do pensamento humano e da realidade } \\
\text { exterior em elementos de natureza material, ou seja, } \\
\text { documentos }\end{array}$ & $\begin{array}{l}\text { Elaboração de manuais de } \\
\text { serviços, normas, portarias e livro } \\
\text { sobre regras de Normalização }\end{array}$ & $\begin{array}{c}\text { Gerência da } \\
\text { biblioteca }\end{array}$ \\
\hline $\begin{array}{c}2 \text { - a conservação, circulação, atualização, catalografia, } \\
\text { descrição e análise de documentos }\end{array}$ & $\begin{array}{l}\text { Catalogação, indexação, } \\
\text { classificação, etiquetação e } \\
\text { conservação curativa }\end{array}$ & $\begin{array}{c}\text { Processamento } \\
\text { técnico e Setor } \\
\text { de reparos }\end{array}$ \\
\hline $\begin{array}{c}3 \text { - a elaboração, com a ajuda de documentos simples, } \\
\text { dos documentos mais complexos, e com a ajuda dos } \\
\text { documentos particulares, o conjunto desses } \\
\text { documentos }\end{array}$ & $\begin{array}{l}\text { Elaboração de fichas } \\
\text { catalográficas; Confecção de } \\
\text { boletins bibliográficos; Descrição } \\
\text { de relatórios sobre serviços e } \\
\text { produtos bibliotecários }\end{array}$ & $\begin{array}{l}\text { Processamento } \\
\text { técnico e } \\
\text { Gerência da } \\
\text { biblioteca }\end{array}$ \\
\hline $\begin{array}{c}4 \text { - o registro dos dados cada vez mais completo, exato, } \\
\text { preciso, simples, direto, rápido, sinótico, de forma } \\
\text { simultaneamente analítica e sintética, seguindo um } \\
\text { plano cada vez mais integral enciclopédico, universal e } \\
\text { mundial }\end{array}$ & $\begin{array}{l}\text { Geração de registros } \\
\text { catalográficos eletrônicos; } \\
\text { Confecção de boletins } \\
\text { bibliográficos; Elaboração de } \\
\text { resumos e resenhas }\end{array}$ & $\begin{array}{l}\text { Processamento } \\
\text { técnico e Setor } \\
\text { de Periódicos }\end{array}$ \\
\hline
\end{tabular}

Fonte: dados da pesquisa (2016).

Observa-se que as atividades realizadas pelos bibliotecários nos diversos setores desenvolvem-se com características semelhantes, em que há intervenção do profissional junto ao documento publicado (livro, periódico, CD e DVD) no sentido de promover a elaboração de elementos capazes de identificar o documento ao ser inserido na coleção. Percebe-se, portando, que as práticas da Documentação sustentam o processo de Representação da Informação. Assim, dialogamos com Novelinho (1996) ao afirmar que essas práticas geram subprodutos ou abreviaturas dos produtos a que correspondem, no intuito de criar uma sistematização, tendo em vista tornar o documento recuperável.

A sistematização de documentos em acervos constitui um fazer minucioso e que requer o uso de técnicas e instrumentos específicos para que estabeleçam os relacionamentos, considerando a sintática e semântica documental, pautadas por meio de uma lógica previamente elaborada, conforme se percebe nos sistemas de classificação relacionais, como a CDU (SOUZA, 2003).

Grosso modo, as práticas documentárias visam a construção de subprodutos (registros) relacionados a um produto (item informacional - documento). Importante destacar que os registros gerados não dizem respeito apenas à representação em códigos alfanuméricos, mas também constitui a materialização do pensamento humano, seja através da geração de novos documentos, como também a elaboração de subprodutos mais abrangentes, como acontece na produção de resumos e resenhas, atividades essas descritas no estudo de Ortega (2004). Esses fazeres caracterizam os profissionais como documentalistas, sendo que, a análise ao regimento interno da biblioteca constatou que em cada setor é exigido a presença de um profissional contratado como "bibliotecário-documentalista".

Além dos princípios documentários elucidados por Otlet, analisaram-se, por meio da observação e pesquisa documental, os produtos e serviços oferecidos na unidade que se sustentam nos ideais de universalização do acesso e compartilhamento da informação, ideia essa alcançada graças ao uso de recursos eletrônicos. O quadro 2 apresenta os ideais de universalização e os produtos e serviços identificados, bem como o setor que os realiza. 


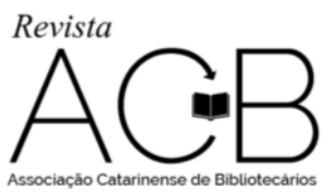

As contribuições da documentação no desenvolvimento das práticas bibliotecárias em biblioteca universitária: diálogos com Paul Otlet - Jorge Santa Anna e Élida Mara Mascarenhas Pieri

Quadro 2 - Identificação dos ideais de universalização propostos por Otlet nas práticas bibliotecárias realizadas com recursos informatizados

\begin{tabular}{|c|c|c|}
\hline $\begin{array}{c}\text { Ideais propostos por Otlet para } \\
\text { universalização do conhecimento }\end{array}$ & $\begin{array}{c}\text { Produtos/serviços documentários } \\
\text { identificados }\end{array}$ & Setor que realiza \\
\hline 1 - Armazenamento universal de informações & $\begin{array}{c}\text { Inserção de registros bibliográficos } \\
\text { em base de dados }\end{array}$ & $\begin{array}{c}\text { Processamento } \\
\text { técnico }\end{array}$ \\
\hline $2-$ Transmissão de informações & $\begin{array}{c}\text { Catálogos de acesso público remoto; } \\
\text { Veículos de comunicação (website, } \\
\text { e-mail) }\end{array}$ & $\begin{array}{c}\text { Processamento } \\
\text { técnico; Setor de } \\
\text { Referência }\end{array}$ \\
\hline 3 - Compartilhamento universal de informações & $\begin{array}{c}\text { Catalogação cooperativa; Redes } \\
\text { sociais (facebook e twitter) }\end{array}$ & $\begin{array}{c}\text { Processamento } \\
\text { técnico; Setor de } \\
\text { referência }\end{array}$ \\
\hline 4 - Atividade centralizada & Catalogação, indexação, & $\begin{array}{c}\text { Processamento } \\
\text { técnico }\end{array}$ \\
\hline
\end{tabular}

Fonte: dados da pesquisa (2016).

Semelhante aos princípios documentários, a maioria dos ideais de universalização são realizados, no âmbito da unidade estudada, no Setor de Processamento técnico, tendo o Setor de Referência contribuição nesse processo, quando gerencia os veículos de comunicação com o usuário. A esse respeito constata-se que as propostas da Documentação não se restringem, tão somente, à elaboração dos registros de representação, mas também, viabilizam formas de aproximação da unidade com o usuário da informação, conforme proposto por Segundo (2001), processo esse concretizado através do uso de redes sociais e canais comunicativos.

Evidencia-se que as propostas formuladas por Otlet no sentido de universalizar o acesso à produção documental produzida no mundo todo são manifestadas com o uso dos recursos informatizados na formulação de acervos eletrônicos disponibilizados na web, sendo essa prática muito comum nas bibliotecas da atualidade, segundo Silva e Freire (2012).

No que se refere aos canais comunicativos, esses instrumentos servem para propagar a existência dos documentos, como também permite que novas informações sejam produzidas, por conseguinte novos conhecimentos e documentos possam ser elaborados a partir do processo de compartilhamento nas redes eletrônicas (SEGUNDO, 2011).

Nota-se que as redes eletrônicas são elementos, os quais permitem que o sonho da universalização do conhecimento seja evidentemente alcançado. O repertório documental de Otlet ganha novas possibilidades de ser ampliado com o uso desses recursos, sendo que as redes sociais funcionam como verdadeiros centros de distribuição, viabilizando a disseminação e produção documental (SEGUNDO, 2011).

Importante mencionar, segundo o autor supracitado, que a única diferença desses ideais com a utilização das redes sociais, principalmente o facebook, está no fato de que tais ideais prezam pela centralização da produção, enquanto que nas redes sociais constatam-se processos descentralizados. Por sua vez, na referida unidade investigada, percebeu-se o processo de centralização no que se refere às atividades de organização da informação realizadas no setor de processamento técnico, proposta essa que caracteriza as práticas documentárias como estratégias de padronização.

\section{CONSIDERAÇÕES FINAIS}

Este estudo permitiu identificar as práticas documentárias realizadas em uma biblioteca universitária considerando os ideais e princípios oriundos da Documentação, através das propostas de Paul Otlet para a organização do conhecimento, permitindo sua universalização.

Em linhas gerais, constataram-se inúmeras práticas documentárias realizadas no ambiente in loco, confirmando que a maioria desses fazeres é realizado no setor de processamento técnico, por meio da elaboração de registros catalográficos, resumos e resenhas, como também a confecção de outros documentos, como manuais de serviço, boletins bibliográficos e livro de Normalização. 


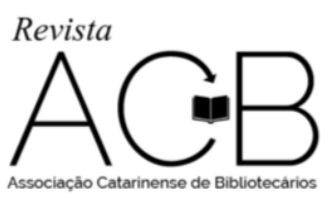

Além disso, a unidade utiliza de recursos informatizados no intuito de permitir uma maior aproximação entre os usuários, tais como catálogos e bases de dados eletrônicos, assim como o uso das redes sociais, de modo que, por meio do compartilhamento, amplia-se o acesso à informação, por conseguinte, a geração de novos conhecimentos e documentos, tendência essa que confirma a concretização dos ideais de universalização propostos por Otlet.

Por fim, com base nesses resultados, evidencia-se a importância que a Documentação provocou no desenvolvimento da Biblioteconomia na sociedade moderna. A manifestação dos fazeres biblioteconômicos nas bibliotecas é fruto do conjunto de atividades proposto por diversas disciplinas e ciências, o que determina à Biblioteconomia um caráter dinâmico, integrado e interdisciplinar, garantindo a sobrevivência dessa prática em uma sociedade altamente instável e competitiva. Assim, sugerem-se novos estudos sobre o trabalho bibliotecário em face de ideais e princípios oriundos de outras disciplinas e ciências, como também a identificação das práticas documentárias em fazeres de outras profissões.

\section{REFERÊNCIAS}

AGUIAR, Giseli Adornato de; SILVA, José Fernando Modesto da. Análise do uso das ferramentas de redes sociais em bibliotecas universitárias brasileiras. CRB-8 Digital, São Paulo, v. 6, n. 1, p. 2-10, ago. 2013. Disponível em:

<http://www.crb8.org.br/UserFiles/File/Artigo_An\%C3\%A1lise\%20do\%20uso\%20das\%20ferramentas\%20 de $\% 20$ redes\%20sociais\%20em\%20bibliotecas\%20universit\%C3\%A1rias\%20brasileiras.pdf $>$. Acesso em: 1 maio 2016.

ARAÚJO, Carlos Alberto Ávila. Ciência da Informação como campo integrador para as áreas de Biblioteconomia, Arquivologia e Museologia. Informação e Informação, Londrina, v. 15, n. 1, p. 173 - 189 , jul./jun. 2010. Disponível em: < http://www.uel.br/revistas/uel/index.php/informacao/article/view/4744>.

Acesso em: 1 maio 2016.

Arquivologia, Biblioteconomia, Museologia e Ciência da Informação: o diálogo possível. Brasília: Briquet de Lemos, 2014.

CARVALHO, Isabel Cristina Louzada. A socialização do conhecimento no espaço das bibliotecas universitárias. Niterói: Intertexto; Rio de Janeiro: Interciência, 2004.

CHAGAS, Joseane; SOUZA, Ieda Maria de. Biblioteca universitaria da UFSC: memória oral e documental. Florianopolis: UFSC, 2002.

CUNHA, Murilo Bastos da. A biblioteca Universitária na encruzilhada. DataGramaZero. Revista de Ciência da Informação, v. 6, n. 1, 2011. Disponível em: <http://dgz.org.br/dez10/Art_07.htm>. Acesso em: 1 maio 2016.

GIL, Antonio Carlos. Como elaborar projetos de pesquisa. 5. ed. São Paulo: Atlas, 2010.

LAKATOS, Eva Maria; MARCONI, Marina de Andrade. Fundamentos de metodologia científica. 5. ed. São Paulo: Atlas, 2003.

LEITÃO, Bárbara Júlia Menezello. Avaliação qualitativa e quantitativa numa biblioteca 


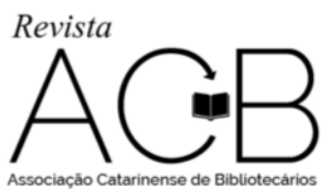

universitária: grupos de foco. Niterói: Intertexto; Rio de Janeiro: Interciência, 2005.

MACIEL, Alba Costa; MENDONÇA, Marília Alvarenga Rocha. Bibliotecas como organizações. 1.ed. rev. Rio de Janeiro: Interciência; Niterói: Intertexto, 2006.

NOVELINHO, Maria Salet Ferreira. Instrumentos e metodologias de representação da informação.

Informação e Informação, Londrina, v. 1, n. 2, p. 37-45, jul./dez. 1996.

OLIVEIRA, M. de (Coord.). Ciência da informação e biblioteconomia: novos conteúdos e espaços de atuação. Belo Horizonte: Ed. da UFMG, 2005.

ORTEGA, Cristina Dota. Relações históricas entre Biblioteconomia, Documentação e Ciência da Informação. DataGramaZero. Revista de Ciência da Informação, v. 5, n. 5, out., 2004. Disponível em: <http://www.dgz.org.br/out04/Art_03.htm>. Acesso em: 1 maio 2016.

OTLET, P. Tratado de documentación: el libro sobre el libro-teoria y práctica. España: Universidad Murcia, 1997.

RAMOS, Maria Etelvina. Por uma política de qualidade nos serviços de informação em bibliotecas universitárias paranaenses. In: (Org.). Tecnologia e novas formas de gestão em bibliotecas universitárias. Ponta Grossa: UEPG, 2000.

SANTA ANNA, Jorge. A biblioteca universitária no presente: de labirinto à encruzilhada em busca da biblioteca híbrida. Revista ACB, Florianópolis, v. 20, n. 1, p. 6-18, jan./abr., 2015. Disponível em: <http://revista.acbsc.org.br/racb/article/view/982/pdf_117>. Acesso em: 1 maio 2016.

Produção científica sobre a temática "gestão de bibliotecas" contemplada na base de periódicos em ciência da informação (BRAPCI): reflexões à luz da literatura. Revista ACB, Florianópolis, v. 21, n. 1, p. 27-45, dez./mar., 2016. Disponível em: < https://revista.acbsc.org.br/racb/article/view/1093>. Acesso em: 1 maio 2016.

SEGUNDO, José Eduardo Santarem. A documentação: Paul Otlet e o facebook. In: CRIPPA, Giulia; MOSTAFA, Solange Puntel (Org.). Ciência da Informação e Documentação. Campinas: Elínea, 2011, p. 99-112.

SILVA, Jonathas Luiz Carvalho; FREIRE, Gustavo Henrique de Araújo. Um olhar sobre a origem da ciência da informação: indícios embrionários para sua caracterização identitária. Encontros Bibli, Florianópolis, v. 17, n. 33, p. 1-29, jan./abr., 2012. Disponível em: < https://periodicos.ufsc.br/index.php/eb/article/view/1518-2924.2012v17n33p1>. Acesso em: 1 maio 2016.

SIQUEIRA, Jéssica Câmara. Biblioteconomia, documentação e ciência da informação: história, sociedade, tecnologia e pós-modernidade. Perspectivas em Ciência da Informação, v. 15, n. 3, p. 52-66, set./dez. 2010. Disponível em: < http://www.scielo.br/pdf/pci/v15n3/04.pdf>. Acesso em: 1 maio 2016.

SOUZA, Sebastião de. CDU: como entender e utilizar a edição-padrão internacional em língua portuguesa. 3. ed. Brasília, DF: Thesaurus, 2004.

VERGARA, S. C. Projetos de Pesquisa em Administração. São Paulo: Atlas, 2007. 
VIEIRA, Diego de Castro; ARDIGO, Julibio David. Paradigmas da biblioteconomia e ciência da informação: estudo de caso em uma unidade de informação especializada. Revista ACB, Florianópolis, v. 20, n. 1, p. 124-137, jan./abr., 2015. Disponível em: < http://revista.acbsc.org.br/racb/article/view/993/pdf_115>. Acesso em: 1 maio 2016.

\title{
THE CONTRIBUTIONS OF DOCUMENTATION IN THE DEVELOPMENT OF LIBRARY PRACTICES IN UNIVERSITY LIBRARIES: DIALOGUES WITH PAUL OTLET
}

\begin{abstract}
This study deals about the documentary practices proposed by the Documentation and reflected by Otlet, and the membership of these practices by the university libraries of contemporaneity. It aims to analyze these practices within a university library, highlighting the products and services offered by said information unit. It presents brief theoretical framework on the principles of documentation based on Otlet theories and conducts documentary research and observation in a real context, given notice / identify, in that context, the documentary practices elucidated in the literature. In general, found to numerous documentary practices carried out in situ environment, confirming that most of these doings is carried out in the technical processing sector, through the development of cataloging records, summaries and reviews, as well as the production of other documents, as service manuals, bulletins and bibliographical Standards book. In addition, the unit uses of computer resources in order to allow a greater approximation between users, such as electronic data catalogs and databases, as well as the use of social networks, so that, through sharing, expands the access to information, thus generating new knowledge and documents, a trend that confirms the completion of the proposed ideals of universalization by Otlet.
\end{abstract}

Keywords: Librarianship. University libraries. Documentation. Documentary practices. Universalization of knowledge.

RECEBIDO EM: 29-07-2016

ACEITO EM: 10-02-2017 